\title{
Graded and ramp protocols present similar results in apparently healthy subjects
}

\section{Protocolo escalonado e de rampa apresentam resultados similares em indivíduos aparentemente saudáveis}

\author{
Thiago Barbosa Lima ${ }^{1,2}$ \\ (D) https://orcid.org/0000-0002-9817-5401 \\ Tony Meireles Santos ${ }^{1}$ \\ (D) https://orcid.org/0000-0002-5242-0117 \\ Vinicius de Oliveira Damasceno ${ }^{3}$ \\ (D) https://orcid.org/0000-0003-0577-9204 \\ Eduardo Zapaterra Campos ${ }^{2}$ \\ (D) https://orcid.org/0000-0002-9356-3683
}

Abstract -The aim of the study was to compare maximum oxygen uptake, maximum heart rate, speed corresponding to $\mathrm{VO}_{2 \max }$, time to exhaustion, and ventilatory thresholds between two maximal test protocols (scaled vs ramp) with equalized metabolic demand in apparently healthy young adults. Twenty-seven subjects of both sexes were analyzed and submitted to two maximum tests: 1) scaled test with $1.2 \mathrm{~km} \cdot \mathrm{h}^{-1}$ every $2 \mathrm{~min} ; 2$ ) ramp test with $0.1 \mathrm{~km} \cdot \mathrm{h}^{-1}$ every $0.18 \mathrm{~min}$; both with $1 \%$ slope and maximum total duration of twenty minutes. Respiratory gas exchanges were directly analyzed, and ventilatory thresholds determined through visual inspection. Central tendency and dispersion measures were adopted, as well as paired t-test and effect size. Bland-Altman analysis verified the agreement among variables. Maximum speed showed significance difference $(\mathrm{p}<0.01)$ for the scaled test $\left(14.0 \pm 1.9 \mathrm{~km} \cdot \mathrm{h}^{-1}\right)$ and ramp test $\left(14.6 \pm 2.3 \mathrm{~km} \cdot \mathrm{h}^{-1}\right)$. Even with small BIAS values, negative trend and high limits of agreement could be observed. Despite the non-difference presented for variables, except for maximum speed, it could be concluded that the scaled test is able to determine the analyzed variables similar to the ramp test, considering the same conditions of the present study.

Key words: Exercise test; Oxygen uptake; Physical fitness.

Resumo - O objetivo do estudo foi comparar o consumo máximo de oxigênio $\left(\mathrm{VO}_{2 \max }\right)$, frequência cardíaca (FC) máxima velocidade associada ao $\mathrm{VO}_{2 \operatorname{mix}}$, tempo até a exaustão e limiares ventilatórios entre dois protocolos de teste máximo (escalonado vs. rampa) com demanda metabólica equalizada em jovens adultos aparentemente saudáveis. Vinte e sete sujeitos de ambos os sexos foram analisados e submetidos à dois testes máximos: 1) escalonado com $1,2 \mathrm{~km} \cdot \mathrm{h}^{-1}$ a cada $2 \mathrm{~min}$; 2) rampa com $0,1 \mathrm{~km} \cdot \mathrm{h}^{-1}$ a cada $0,18 \mathrm{~min}$; ambos com $1 \%$ de inclinação e duração total máxima prevista de vinte minutos. As trocas respiratórias foram analisadas diretamente, e os limiares ventilatórios determinados por inspeção visual. Medidas de tendência central e dispersão foram adotadas, assim como um teste t pareado e tamanho do efeito. A análise de Bland-Altman verificou a concordância entre as variáveis. A única variável a apresentar diferença estatística $(\mathrm{p}<0,01)$ foi a velocidade máxima (escalonado $=14,0 \pm 1,9$ $\left.\mathrm{km} \cdot \mathrm{h}^{-1}\right)$ e $\left(\mathrm{rampa}=14,6 \pm 2,3 \mathrm{~km} \cdot \mathrm{h}^{-1}\right)$. Mesmo com baixos valores de BIAS, é possível verificar uma tendência negativa assim como altos limites de concordância. Apesar da não diferença apresentada para as variáveis, exceto para a velocidade máxima, é possível afirmar que o teste escalonado é capaz de determinar as variáveis analisadas de modo semelhante ao teste rampa considerando as mesmas condições do presente estudo.

Palavras-chave: Aptidão física; Consumo de oxigênio; Teste de esforço.
1 Federal University of Pernambuco. Performance and Health Research Center. Recife, PE. Brazil.

2 Federal University of Pernambuco. Sports Performance Research Group. Recife PE. Brazil.

3 Federal University of Pernambuco. Physical Exercise and Technology Research Group. Recife PE. Brazil.

Received: July 07, 2018 Accepted: October 19, 2019

How to cite this article Lima TB, Santos TM, Damasceno V0, Campos EZ. Graded and ramp protocols present similar results in apparently healthy subjects. Rev Bras Cineantropom Desempenho Hum 2020, 22:e57565. DOI: http://dx.doi.org/10.1590/19800037.2020v22e57565

Copyright: This work is licensed under a Creative Commons Attribution 4.0 International License. 


\section{INTRODUCTION}

Cardiorespiratory fitness is one of the physical fitness components ${ }^{1}$. Individuals with low levels of cardiorespiratory fitness have increased risks associated with sudden death regardless of cause, while higher levels of cardiorespiratory fitness can reduce these risks ${ }^{1-5}$. Maximum oxygen uptake $\left(\mathrm{VO}_{2 \max }\right)$ is one of the variables derived from cardiorespiratory assessment, being directly (ergospirometry) or indirectly (estimate) determined with tests conducted at maximum or submaximal intensity, or even through questionnaires ${ }^{1,3,6}$.

The protocols most used by Balke and Ware ${ }^{7}$, Ellestad et al. ${ }^{8}$ and Bruce ${ }^{9}$ have progressive increase in intensity; however, they have different configurations. More recently, with technological advances, it has been possible to develop scaled tests $\left(\mathrm{T}_{\mathrm{ESC}}\right)$, which are similar to traditional tests, but with greater refinement and accuracy ${ }^{10-13}$. Among the possible modifications, initial speed and / or percentage of initial inclination, increment rate per stage in both speed and inclination percentage, stage duration, in addition to time to exhaustion $\left(\mathrm{T}_{\text {total }}\right)$ can be highlighted ${ }^{14}$.

However, searching for an alternative to classic assessment models, Whipp et al. ${ }^{15}$ proposed a new ramp test model $\left(\mathrm{T}_{\mathrm{RAMP}}\right)$ in cycle ergometer. $\mathrm{T}_{\text {RAMP }}$ showed higher $\mathrm{VO}_{2 \max }$ values $\left(3.19 \pm 0.31\right.$ and $3.24 \pm 0.31 \mathrm{~mL} \cdot \mathrm{kg}^{-}$ ${ }^{1} \cdot \mathrm{min}^{-1}$ ) when compared to $\mathrm{T}_{\mathrm{ESC}}$. In addition, the authors observed better linearity between $\mathrm{VO}_{2}$ and heart rate (HR), above and below ventilatory thresholds, better reproducibility of ventilatory thresholds and greater time / efficiency ratio ${ }^{15}$. Subsequently, Myers et al. ${ }^{16}$ found for $\mathrm{T}_{\text {RAMP }}$ greater association between $\mathrm{VO}_{2}$ and work rate $(0.80$ and 0.78$)$ and lower standard error of the estimate $\left(2.5\right.$ and $\left.1.7 \mathrm{~mL} \cdot \mathrm{kg}^{-1} \bullet \mathrm{min}^{-1}\right)$ on treadmill and cycle ergometer, respectively. From these studies, the $\mathrm{T}_{\text {RAMP }}$ model would present greater accuracy with more individualized character based on the predetermination of initial and final speeds, as well as the $T_{\text {total }}$ considering the level of physical fitness of participants ${ }^{17,18}$.

Other studies have compared the physiological responses presented by $\mathrm{T}_{\text {ESC }}$ and $\mathrm{T}_{\text {RAMP }}$. However, such comparisons were based on different work intensity configurations ${ }^{19-22}$, with stages not equivalent in terms of metabolic demand between protocols. Based on the above, the non-equalization of initial efforts and increment rates can make it difficult to define the best and most appropriate testing strategy to be followed, since the simple manipulation of a single variable of the test protocol can lead to different responses for the same subjects. Thus, the aim of the study was to compare maximum oxygen uptake $\left(\mathrm{VO}_{2 \max }\right)$, maximum heart rate $\left(\mathrm{HR}_{\max }\right)$, speed associated with $\mathrm{VO}_{2 \max }\left(\mathrm{vVO}_{2 \max }\right)$ time to exhaustion and ventilatory thresholds between two maximum test protocols with equalized metabolic demand in apparently healthy young adults. Our hypothesis suggests that protocols with equalized initial and final metabolic demands present similar physiological and performance responses. 


\section{METHOD}

\section{Participants}

Sample size was calculated by the $\mathrm{G}^{*}$ Power software, version 3.1.0, Germany using effect size of 0.50 , alpha error of 0.05 and power of 0.80 , which values required 27 participants. Fifty-one participants were recruited, of which 24 were excluded for not completing all necessary visits. Thus, 27 Physical Education students participated in this study, among which 17 were men $\left(23.5 \pm 4.6\right.$ years, $69.4 \pm 7.5 \mathrm{~kg}, 1.87 \pm 0.16 \mathrm{~m}, 23.5 \pm 2.6 \mathrm{~kg} \cdot \mathrm{m}^{-2}$ and $\left.52.9 \pm 8.0 \mathrm{~mL} \cdot \mathrm{kg}^{-1} \cdot \mathrm{min}^{-1}\right)$ and 10 were women $(22.7 \pm 2.4$ years, 60.5 $\pm 5.7 \mathrm{~kg}, 1.63 \pm 0.15 \mathrm{~m}, 22.7 \pm 2.1 \mathrm{~kg}^{\bullet} \mathrm{m}^{-2}$ and $\left.41.2 \pm 4.8 \mathrm{~mL} \cdot \mathrm{kg}^{-1} \bullet \mathrm{min}^{-1}\right)$. Participants were selected for convenience in a non-probabilistic way. For inclusion, low-risk classification according to $\mathrm{ACSM}^{1}$ and ability to run on a treadmill at minimum speed of $8 \mathrm{~km} \cdot \mathrm{h}^{-1}$ were adopted as criterion. Individuals who used some type of medication and who had some type of physical limitation were excluded. In addition, it was suggested that participants should not perform vigorous exercise prior to evaluations (24 h), eat foods of difficult digestion ( $3 \mathrm{~h}$ ) or use stimulants (6 h).

\section{Study design}

A cross-sectional study was carried out during three visits in order to facilitate the comparison between scaled and ramp tests. In the first, shortly after signing the informed consent form and risk stratification, anthropometric measurements of body mass and height were performed. Then, heart rate and blood pressure at rest were measured and familiarization with tests was conducted. Tests were randomly performed on the second and third visits, always at the same time of day. The study was previously approved by the Research Ethics Committee of the Federal University of Pernambuco (protocol \# 553.851).

\section{Procedures}

\section{- Anthropometry}

Measurements of body mass (digital scale, Filizola ${ }^{\circledR}$, Brazil), height (stadiometer, Sanny ${ }^{\circledR}$, Brazil) were determined with accuracy of $0.1 \mathrm{~kg}$ and $0.01 \mathrm{~cm}$, respectively.

\section{- Scaled test}

Considering load increment between stages equivalent to 1 MET ( $\left.3.5 \mathrm{~mL} \cdot \mathrm{kg}^{-1} \bullet \mathrm{min}^{-1}\right)$, the protocol was elaborated from the $\mathrm{VO}_{2 \max }$ prediction equation for running on a treadmill of ACSM $^{1}$ (Super ATL, InbraSport ${ }^{\circledR}$, Brazil). Thus, seeking to include subjects of moderate to high conditioning, $8.5 \mathrm{~km} \bullet \mathrm{h}^{-1}$ was adopted as the initial speed and $19.3 \mathrm{~km} \bullet \mathrm{h}^{-1}$ as the final speed, and increments of $1.2 \mathrm{~km} \cdot \mathrm{h}^{-1}$ per stage with fixed inclination at $1 \%{ }^{23}$. The duration per stage was two minutes ${ }^{10}$ and estimated total test time was twenty minutes. Warm-up was conducted at speed of 4.5 and $5.5 \mathrm{~km} \bullet \mathrm{h}^{-1}$ for two and one minute, respectively, and recovery at speed of 
$4.5 \mathrm{~km} \cdot \mathrm{h}^{-1}$ for three minutes. The laboratory temperature was maintained at $\pm 22{ }^{\circ} \mathrm{C}$ and the relative humidity between 40 and $60 \%$ (Analog Thermo-Hygrometer Dry and Wet Bulb, Incoterm ${ }^{\circledR}$, Brazil).

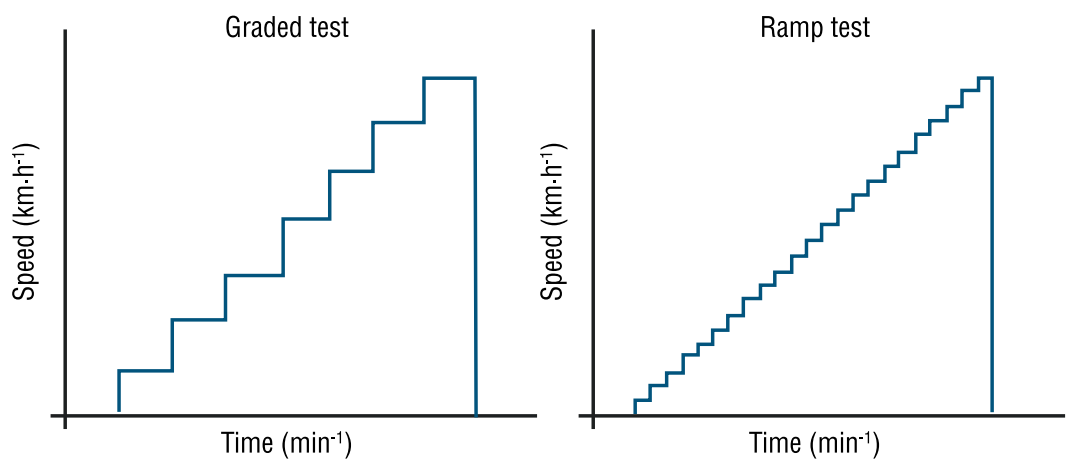

Figure 1. Scheme of speed vs. time progression of Scaled and Ramp Tests

\section{- Ramp test}

The test has design similar to the scaled test: warm-up and recovery phase, initial and final speed, as well as the total estimated time. However, the increment rate per stage was $0.01 \mathrm{~km} \cdot \mathrm{h}^{-1}$ every $0.18 \mathrm{~min}(10.8 \mathrm{~s})$, performed in an automated way (ErgoControl, InbraSport ${ }^{\circledR}$, Brazil).

\section{- Respiratory gas exchanges}

There was direct monitoring of respiratory gas exchange variables $\left(\mathrm{VO}_{2}\right.$, $\mathrm{VCO}_{2}$ and $\mathrm{VE}$ ) through the $\mathrm{VO}_{2000}$ gas analyzer (Sensor Medics Intruments ${ }^{\circledR}$, USA) with average every ten seconds. The equipment was calibrated before each test based on manufacturer's instructions. The test interruption followed criteria suggested by ACSM ${ }^{1}$ for testing without diagnostic purposes. For $\mathrm{VO}_{2 \max }$ determination, the highest value obtained during the test was considered. In addition, secondary criteria were observed to define maximum effort, namely: maximum voluntary interruption, $\mathrm{HR}_{\max }>85 \%$ of predicted, respiratory quotient $>1.1$ and perceived effort $>9$ on the $0-10^{1}$ scale.

\section{- Ventilatory thresholds - VT ${ }_{1}$ and VT $T_{2}$}

Data were plotted separately as a function of time for each $30 \mathrm{~s}$. Values referring to the first and second linearity breaks for $\mathrm{VE}$ were observed, as well as the lowest value observed for $\mathrm{VE} / \mathrm{VO}_{2}$ and $\mathrm{VE} / \mathrm{VCO}_{2}$ before the systematic increase of $\mathrm{VT}_{1}$ and $\mathrm{VT}_{2}$, respectively ${ }^{24}$. Coincident values between two evaluators were considered after visual inspection and in case of disagreement, a third evaluator was consulted.

\section{- Heart rate}

According to $\mathrm{ACSM}^{1}$ recommendations, resting $\mathrm{HR}$ was verified in supine position for 5 min using frequency meter (FT1, Polar ${ }^{\circledR}$, Finland). HR was monitored and recorded during the entire test by sensor coupled to the $\mathrm{VO}_{2000}$ device (Sensor Medics Intruments ${ }^{\circledR}$, USA). 


\section{Statistical analysis}

The characteristics of subjects were presented as mean \pm standard deviation. The Shapiro-Wilk test was used to verify data normality. A paired t-test was adopted to compare the means of maximum $\left(\mathrm{VO}_{2 \max }, \mathrm{HR}_{\max }\right.$, $\mathrm{vVO}_{2 \max }$ and $\left.\mathrm{T}_{\text {total }}\right)$ and submaximal variables $\left(\mathrm{VO}_{2}, \mathrm{HR}\right.$ and $\mathrm{vVO}_{2}$ for $\mathrm{VT}_{1}$ and $\mathrm{VT}_{2}$ ), and the Cohen's effect size (ES) was also evaluated ( 0.20 small; 0.50 medium; > 0.80 large). In addition, visual inspection was performed using the Bland-Altman ${ }^{25}$ graph and the BIAS value to verify the agreement between variables. Analyses were performed using the IBM SPSS software version 23.0 and figures were made using the Graph Pad Prism software version 5.01. The significance level was set at $\mathrm{p}<0.05$.

\section{RESULTS}

Table 1 presents the descriptive analysis (mean \pm standard deviation), $t$ test, $\mathrm{p}$ value and $\mathrm{ES}$ for maximum and submaximal variables in both tests. $\mathrm{V}_{\mathrm{V}} \mathrm{V}_{2 \max }$ was the only variable that showed significant difference $\left(\mathrm{t}_{(26)}=-3.04\right.$ and $\mathrm{p}=0.01)$ between $\mathrm{T}_{\mathrm{ESC}}\left(14.0 \pm 1.9 \mathrm{~km} \bullet \mathrm{h}^{-1}\right)$ and $\mathrm{T}_{\text {RAMP }}\left(14.6 \pm 2.3 \mathrm{~km} \bullet \mathrm{h}^{-1}\right)$. Although the study presented sample composed of both sexes, analysis showed that the existing difference remained in ${ }_{\mathrm{V}} \mathrm{VO}_{2 \max }$ for men $(\mathrm{t}(16)=$ -2.337 and $p=0.03$ ) and in $\mathrm{HR}_{\max }$ for women $(\mathrm{t}(9)=3.00$ and $\mathrm{p}=0.02)$.

Figure 2 shows the residual Bland-Altman scores for maximum and submaximal variables of both tests. In all tests, BIAS showed low difference between measurements and it was possible to observe a negative trend as the mean values increase. On the other hand, the limits of agreement showed high values.

Table 1. Descriptive analysis, $t$ test and effect size of maximum (V02, HR, vV02 and Ttotal) and submaximal variables (V02, HR and speed) $(n=27)$.

\begin{tabular}{|c|c|c|c|c|c|c|c|c|c|c|}
\hline \multirow{2}{*}{ Variables } & & \multicolumn{3}{|c|}{$\mathrm{T}_{\mathrm{ESC}}$} & \multicolumn{3}{|c|}{$\mathrm{T}_{\text {RAMP }}$} & \multirow{2}{*}{$\mathrm{t}_{(26)}$} & \multirow{2}{*}{$p$} & \multirow{2}{*}{ ES } \\
\hline & & Mean & \pm & SD & Mean & \pm & SD & & & \\
\hline \multicolumn{11}{|l|}{ Maximum } \\
\hline $\mathrm{VO}_{2 \max }$ & $\left(\mathrm{mL} \cdot \mathrm{kg}^{-1} \cdot \mathrm{min}^{-1}\right)$ & 48.5 & \pm & 9.0 & 48.5 & \pm & 10.7 & 0.06 & 0.95 & 0 \\
\hline $\mathrm{HR}_{\max }$ & (bpm) & 192 & \pm & 6.3 & 191 & \pm & 7.3 & 0.99 & 0.33 & 0.1 \\
\hline $\mathrm{VVO}_{2 \max }$ & $\left(\mathrm{km} \cdot \mathrm{h}^{-1}\right)$ & 14.0 & \pm & 1.9 & 14.6 & \pm & 2.3 & -3.04 & $0.01^{*}$ & 0.1 \\
\hline $\mathrm{T}_{\text {total }}$ & (min) & 11.4 & \pm & 3.2 & 11.7 & \pm & 4.3 & -1.09 & 0.29 & 0 \\
\hline \multicolumn{11}{|l|}{$\mathrm{VT}_{1}$} \\
\hline $\mathrm{VO}_{2}$ & $\left(\mathrm{~mL} \cdot \mathrm{kg}^{-1} \cdot \mathrm{min}^{-1}\right)$ & 34.9 & \pm & 7.6 & 34.6 & \pm & 6.7 & 0.25 & 0.80 & 0 \\
\hline $\mathrm{HR}$ & (bpm) & 164 & \pm & 8.9 & 162 & \pm & 12.5 & 0.88 & 0.39 & 0.1 \\
\hline Speed & $\left(\mathrm{km} \cdot \mathrm{h}^{-1}\right)$ & 10.2 & \pm & 1.0 & 10.6 & \pm & 1.3 & -1.19 & 0.07 & 0.2 \\
\hline \multicolumn{11}{|l|}{$\mathrm{VT}_{2}$} \\
\hline $\mathrm{VO}_{2}$ & $\left(\mathrm{~mL} \cdot \mathrm{kg}^{-1} \cdot \mathrm{min}^{-1}\right)$ & 42.3 & \pm & 8.0 & 42.1 & \pm & 8.5 & 0.14 & 0.89 & 0 \\
\hline $\mathrm{HR}$ & (bpm) & 181 & \pm & 7.8 & 179 & \pm & 10.8 & 0.97 & 0.34 & 0.1 \\
\hline Speed & $\left(\mathrm{km} \cdot \mathrm{h}^{-1}\right)$ & 12.5 & \pm & 1.4 & 12.3 & \pm & 1.5 & 0.57 & 0.57 & 0.1 \\
\hline
\end{tabular}

Note. $\mathrm{T}_{\text {ESC }}$ - scaled test; $\mathrm{T}_{\text {RAMP }}$ - ramp test; $\mathrm{VO}_{2 \max }$ - maximum oxygen uptake; HRmax - maximum heart rate; $v V 02 m a x$ - maximum speed when reaching $V_{O_{2 a x}} ; T_{\text {total }}$ - time to exhaustion; $V T_{1}$ - first ventilatory threshold; $\mathrm{VT}_{2}$ - second ventilatory threshold; $\mathrm{VO}_{2}$ - Oxygen uptake at $\mathrm{VT}_{1}$ and $\mathrm{VT}_{2} ; \mathrm{HR}$ - heart rate at $\mathrm{VT}_{1}$ and $\mathrm{VT}_{2}^{2}$. SD - standard deviation; $\mathrm{t}$ - student's t test; $\mathrm{p}$ - statistical significance $<0.05 ;{ }^{*}$ - presence of statistical difference; ES - effect size. 

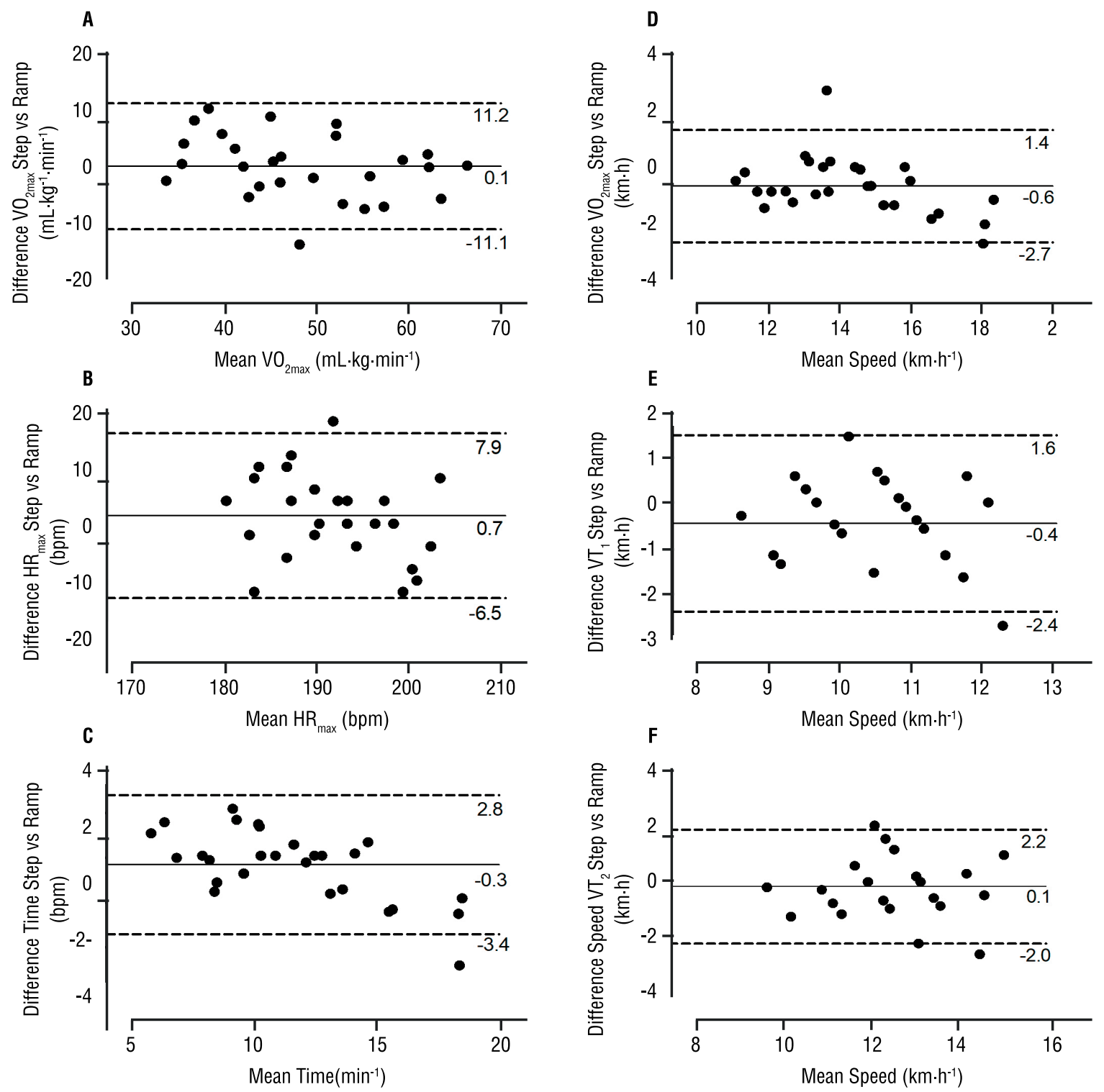

Figure 2. Residual scores (Bland-Altman) of maximum and submaximal variables in both tests. A - Maximum oxygen uptake; B Maximum heart rate; C - Time to exhaustion; D - Maximum speed; E - Speed at 1st ventilatory threshold; F - Speed at 2nd ventilatory threshold; solid line - BIAS; dashed line - 95\% agreement interval.

\section{DISCUSSION}

The present study aimed to compare submaximal and maximum physiological responses between scaled and ramp protocols, equalized by metabolic demand, in apparently healthy young adults. The main findings of the present study were: (i) no difference was found for $\mathrm{VO}_{2 \max }, \mathrm{HR}_{\max }$ and $\mathrm{T}_{\text {total }}$ between $\mathrm{T}_{\mathrm{ESC}}$ and $\mathrm{T}_{\mathrm{RAMP}}$, (ii) $\mathrm{vVO}_{2 \max }$ was lower in $\mathrm{T}_{\mathrm{ESC}}$ than in $\mathrm{T}_{\mathrm{RAMP}}$; (iii) limits of agreement were high despite the average difference being below one unit for all variables; and (iv) the magnitude of differences determined by the effect size was trivial for all variables.

As observed, $\mathrm{VO}_{2 \max }$ values did not differ for both tests $(\mathrm{p}=0.95)$. In the study by Kirkeberg et al. ${ }^{11}$, no difference in $\mathrm{VO}_{2 \max }$ was found when 
different $T_{\text {total }}$ values were adopted (short $=9.2 \pm 1.2$ min; medium $=10.8$ $\pm 1.3 \mathrm{~min}$; long $=13.1 \pm 2.3 \mathrm{~min}$ ) in a $\mathrm{T}_{\mathrm{ESC}}$. These findings corroborate those of the present study, which presented $\mathrm{T}_{\text {total }}(11.4 \pm 3.2 \mathrm{~min}$ and 12.1 $\pm 4.2 \mathrm{~min}$ ) close to that traditionally suggested. Sperlich et al. ${ }^{22}$ compared five maximum tests (three on a ramp, one scaled and one self-selected) and observed that only $\mathrm{T}_{\text {ESC }}$ showed $\mathrm{T}_{\text {total }}(25.3 \pm 3 \mathrm{~min})$ value significantly higher than the others. It was possible to identify that $\mathrm{T}_{\mathrm{ESC}}$ and $\mathrm{T}_{\mathrm{RAMP}}$ presented low BIAS values $\left(0.1 \mathrm{~mL} \cdot \mathrm{kg}^{-1} \cdot \mathrm{min}^{-1}\right.$ and $\left.-0.3 \mathrm{~min}\right)$; however, the limits of agreement (-11.1 to $11.2 \mathrm{~mL} \cdot \mathrm{kg}^{-1} \cdot \mathrm{min}^{-1}$ and -3.4 to $2.8 \mathrm{~min}$ ) indicated variation greater than $10 \%$ for $\mathrm{VO}_{2 \max }$. This variation may be associated with $\mathrm{T}_{\text {total }}$, since higher $\mathrm{T}_{\text {total }}$ may reflect lower $\mathrm{VO}_{2 \max }$ values ${ }^{22}$.

$\mathrm{vVO}_{2 \max }$ was the only variable to present significant difference $(\mathrm{p}=0.01)$ between the two investigated protocols. This difference is supported by the way in which increments were performed in both tests, despite initial and final (proposed) speeds of both protocols being the same. Similarly, Machado et al. ${ }^{12}$ compared different times per stage in a $T_{\text {ESC }}(1,2$ and $3 \mathrm{~min}$ ) and observed significant difference in the final speed when $1 \mathrm{~min}$ $\left(18.3 \pm 1.6 \mathrm{~km} \cdot \mathrm{h}^{-1} ; \mathrm{p}<0.05\right)$ and $2 \min \left(16.9 \pm 1.6 \mathrm{~km} \cdot \mathrm{h}^{-1} ; \mathrm{p}<0.05\right)$ were adopted. Peserico et al. ${ }^{13}$ compared different increment rates $(0.5 ; 1$ and $\left.2 \mathrm{~km} \cdot \mathrm{h}^{-1}\right)$ in a $T_{\text {ESC }}$ and observed that greater increments reflected higher speeds $\left(16.4 \pm 0.8 ; 15.6 \pm 0.7\right.$ and $14.6 \pm 0.7 \mathrm{~km} \cdot \mathrm{h}^{-1}$, respectively). $\mathrm{vVO}_{2 \max }$ showed negative mean difference, reflecting higher final speed for $\mathrm{T}_{\text {RAMP, }}$, also showing higher limits of agreement, exceeding the increment rate proposed per stage. Different values associated with $\mathrm{vVO}_{2 \max }$ can impair its interpretation, consequently influencing the exercise prescription, especially in intermittent high-intensity exercises ${ }^{26}$.

The non-difference observed in $\mathrm{HR}_{\mathrm{ma}} \mathrm{x}$ in both tests is similar to findings of other studies. Peserico et al. ${ }^{27}$ did not observe significant difference when different increment rates per stage were adopted. Vucetic et al. ${ }^{28}$ compared two $T_{\text {RAMP }}$ with lower and higher increment rate $\left(1 \mathrm{~km} \cdot \mathrm{h}^{-1}\right.$ every $30 \mathrm{~s}$ vs. $1 \mathrm{~min}$ ) and also found no significant difference. However, Kirkeberg et al. ${ }^{11}$ observed significant difference when the longest test $(189 \pm 7.1 \mathrm{bpm} ; \mathrm{p}<0.05)$ was compared to the shortest test (short $=188$ $\pm 9.6 \mathrm{bpm}$; medium $=186 \pm 9.7 \mathrm{bpm}$ ). The agreement between methods can be observed considering that the difference (BIAS $=0.7 \mathrm{bpm}$ ) was below $1 \mathrm{bpm}$ between tests, although differences of up to eight beats were observed through the limits of agreement. A possible explanation for this variation can be attributed to the way in which load increments per stage influenced the responses of the autonomic nervous system in the search for homeostasis. Thus, future studies should investigate possible interference of the stage manipulation strategy on heart rate modulation.

Considering the $\mathrm{VT}_{1}$ and $\mathrm{VT}_{2}$ determination, no significant difference was observed between tests. Vucetic et al. ${ }^{28}$ found no difference when adopting the V-slope methods, respiratory equivalent and HR deflection point in $\mathrm{T}_{\text {RAMP }}$ with lower or higher increment rate. Similarly, Zuniga et al. ${ }^{29}$ did not observe statistical difference between algorithm-based regres- 
sion methods (deflection point, $\mathrm{V}$-slope and $\mathrm{D}$-max) to determine the ventilatory threshold in $\mathrm{T}_{\mathrm{ESC}}$ and $\mathrm{T}_{\mathrm{RAMP}}$. When comparing the residual scores between tests, difference of less than $0.5 \mathrm{~km} \cdot \mathrm{h}^{-1}$ can be verified for $\mathrm{VT}_{1}\left(\mathrm{BIAS}=-0.4 \mathrm{~km} \cdot \mathrm{h}_{-1}\right)$ and $\mathrm{VT}_{2}$ determination (BIAS $\left.=0.1 \mathrm{~km} \cdot \mathrm{h}-1\right)$. However, there was greater variation in the limits of agreement.

In practical terms, the use of $\mathrm{T}_{\mathrm{ESC}}$ proved to be statistically similar to $T_{\text {RAMP }}$. Since $T_{\text {RAMP }}$ does not require equipment with specific resources, its use seems to be recommended on a large scale when considering cost minimization. To the detriment of many recommendations for the adoption of the ramp protocol, the results presented here do not support this appeal, being up to the professional the free choice on which protocol to adopt, as long as there is no change in the type of test during reassessment.

As a limitation for the present study, the adoption of sample including both sexes can be considered. However, it should be highlighted that it was not the focus of this study to compare physiological responses in a distinct way, thus adopting a more generalized analysis approach. Furthermore, the magnitudes of the limits of agreement in the Bland-Altman analyses stand out, which seem to point to aspects of individual variability in responses, which should be investigated in future studies. Thus, the results presented here are restricted to young and apparently healthy adults of both sexes. Future studies should investigate the findings produced here in other clinical contexts and age groups.

\section{CONCLUSION}

Given the non-observance of statistical difference, except for variable $\mathrm{vVO}_{2 \max }$, it could be inferred that $\mathrm{T}_{\mathrm{ESC}}$ is similar to $\mathrm{T}_{\text {RAMP }}$ for determining the study variables, since both protocols have equivalent metabolic demands, which is not in line with many recommendations that $T_{\text {RAMP }}$ is more effective than $\mathrm{T}_{\mathrm{ESC}}$. Thus, the option for a given protocol, considering an adequate decision on its initial and final metabolic demand and consequent increment rate, may be at the discretion of the professional for evaluation based on personal preferences and availability of resources. Finally, for the prescription of physical training based on results, it should be considered that $\mathrm{T}_{\text {RAMP }}$ will provide higher $\mathrm{vVO}_{2 \max }$ values.

\section{COMPLIANCE WITH ETHICAL STANDARDS}

\section{Funding}

This research did not receive any specific grant from funding agencies in the public, commercial, or non-profit sectors. This study was funded by the authors

\section{Ethical approval}

Ethical approval was obtained from the local Human Research Ethics Committee - Federal University of Pernambuco and the protocol (no. 553.851) was written in accordance with standards set by the Declaration of Helsinki. 


\section{Conflict of interest statement}

The authors have no conflict of interests to declare.

\section{Author Contributions}

Conceived and designed the experiments: TBL and TMS. Performed the experiments: TBL. Analyzed the data: TBL, TMS, VOD and EZC. Contributed reagents/materials/analysis tools: TBL and TMS. Wrote the paper: TBL

\section{REFERENCES}

1. ACSM. ACSM's Guidelines for Exercise Testing and Prescription. 10 ed. Philadelphia Wolters Kluwer/Lippincott Williams \& Wilkins Health; 2017. 472 p.

2. Arena R, Myers J, Williams MA, Gulati M, Kligfield P, Balady GJ, et al. Assessment of functional capacity in clinical and research settings: a scientific statement from the American Heart Association Committee on Exercise, Rehabilitation, and Prevention of the Council on Clinical Cardiology and the Council on Cardiovascular Nursing. Circulation 2007;116(3):329-43.

3. Beltz NM, Gibson AL, Janot JM, Kravitz L, Mermier CM, Dalleck LC. Graded Exercise Testing Protocols for the Determination of VO2max: Historical Perspectives, Progress, and Future Considerations. J Sports Med 2016;2016:3968393.

4. Boone J, Bourgois J. The oxygen uptake response to incremental ramp exercise: methodogical and physiological issues. Sports Med 2012;42(6):511-26.

5. Stringer WW. Cardiopulmonary exercise testing: current applications. Expert Rev Respir Med 2010;4(2):179-88.

6. Poole DC, Jones AM. Measurement of the maximum oxygen uptake Vo2max: Vo2peak is no longer acceptable. J Appl Physiol 2017;122(4):997-1002.

7. Balke B, Ware RW. An experimental study of physical fitness of Air Force personnel. U S Armed Forces Med J 1959;10(6):675-88.

8. Ellestad MH, Allen W, Wan MC, Kemp GL. Maximal treadmill stress testing for cardiovascular evaluation. Circulation 1969;39(4):517-22.

9. Bruce RA. Exercise testing of patients with coronary heart disease. Principles and normal standards for evaluation. Ann Clin Res 1971;3(6):323-32.

10. Kuipers H, Rietjens G, Verstappen F, Schoenmakers H, Hofman G. Effects of stage duration in incremental running tests on physiological variables. nt J Sports Med 2003;24(7):486-91.

11. Kirkeberg JM, Dalleck LC, Kamphoff CS, Pettitt RW. Validity of 3 protocols for verifying VO2 max. Int J Sports Med 2011;32(4):266-70.

12. Machado FA, Kravchychyn AC, Peserico CS, da Silva DF, Mezzaroba PV. Incremental test design, peak 'aerobic' running speed and endurance performance in runners. J Sci Med Sport 2013;16(6):577-82.

13. Peserico CS, Zagatto AM, Machado FA. Evaluation of the Best-designed Graded Exercise Test to Assess Peak Treadmill Speed. Int J Sports Med 2015;36(9):729-34.

14. Julio UF, Panissa VLG, Shiroma SA, Franchini E. Effect of Protocol Manipulation for Determining Maximal Aerobic Power on a Treadmill and Cycle Ergometer. Strength Cond J 2017;39(5):58-71.

15. Whipp BJ, Davis JA, Torres F, Wasserman K. A test to determine parameters of aerobic function during exercise. J Appl Physiol 1981;50(1):217-21.

16. Myers J, Buchanan N, Walsh D, Kraemer M, McAuley P, Hamilton-Wessler $\mathrm{M}$, et al. Comparison of the ramp versus standard exercise protocols. J Am Coll Cardiol 1991;17(6):1334-42.

17. Myers J, Bellin D. Ramp exercise protocols for clinical and cardiopulmonary exercise testing. Sports Med 2000;30(1):23-9. 
18. Buchfuhrer MJ, Hansen JE, Robinson TE, Sue DY, Wasserman K, Whipp BJ. Optimizing the exercise protocol for cardiopulmonary assessment. J Appl Physiol Respir Environ Exerc Physiol 1983;55(5):1558-64.

19. Bader DS, Maguire TE, Balady GJ. Comparison of ramp versus step protocols for exercise testing in patients $>$ or $=60$ years of age. Am J Cardiol 1999;83(1):11-4.

20. Bhadha K, Walter JD, DiMarzio D, Cave V, Cassel D, Heo J, et al. Comparison of the Bruce and ramp protocols in the assessment of left ventricular performance during exercise in healthy women. Am J Cardiol 1995;75(14):963-6.

21. Noel M, Jobin J, Poirier P, Dagenais GR, Bogaty P. Different thresholds of myocardial ischemia in ramp and standard bruce protocol exercise tests in patients with positive exercise stress tests and angiographically demonstrated coronary arterial narrowing. Am J Cardiol 2007;99(7):921-4.

22. Sperlich PF, Holmberg HC, Reed JL, Zinner C, Mester J, Sperlich B. Individual versus Standardized Running Protocols in the Determination of VO2max. J Sports Sci Med 2015;14(2):386-93.

23. Jones AM, Doust JH. A $1 \%$ treadmill grade most accurately reflects the energetic cost of outdoor running. J Sports Sci 1996;14(4):321-7.

24. Pires FO, Lima-Silva AE, Oliveira FRd. Differences among variables of determination of vantilatory thresholds. Rev Bras Cineantropom Desempenho Hum. 2006;7(2):9.

25. Bland JM, Altman DG. Statistical methods for assessing agreement between two methods of clinical measurement. Lancet 1986;1(8476):307-10.

26. Buchheit M, Laursen PB. High-intensity interval training, solutions to the programming puzzle: Part I: cardiopulmonary emphasis. Sports Med 2013;43(5):313-38.

27. Peserico CS, Zagatto AM, Machado FA. Reproducibility of heart rate and rating of perceived exertion values obtained from different incremental treadmill tests. Sci Sports 2015;30(2):82-8.

28. Vucetic V, Sentija D, Sporis G, Trajkovic N, Milanovic Z. Comparison of ventilation threshold and heart rate deflection point in fast and standard treadmill test protocols. Acta Clin Croat 2014;53(2):190-203.

29. Zuniga JM, Housh TJ, Camic CL, Bergstrom HC, Schmidt RJ, Johnson GO. The effect of different exercise protocols and regression-based algorithms on the assessment of the anaerobic threshold. J Strength Cond Res 2014;28(9):2507-12.

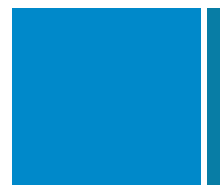

Corresponding author

Eduardo Zapaterra Campos

245, Juornalist Aníbal Fernandes Avenue,

University City, Recife - PE. Zip Code: 50670-901

Email: eduardo.zapaterracampos@ufpe.br 